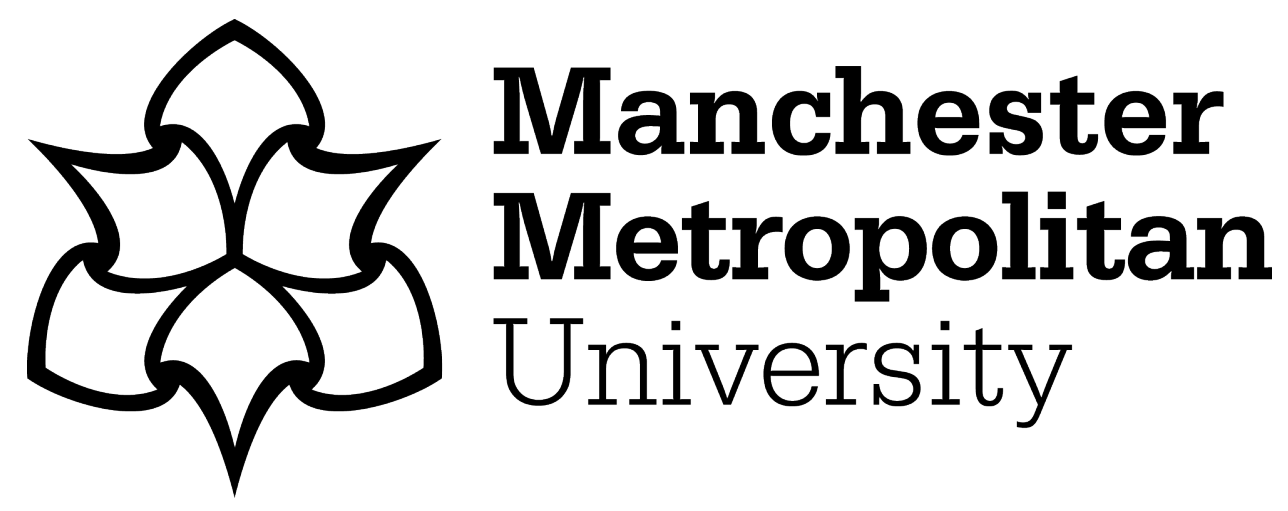

Badwan, Khawla ORCID logoORCID: https://orcid.org/0000-0003-1808724X and Hall, Elisha (2020) Walking along in sticky places: post-humanist and affective insights from a reflective account of two young women in Manchester, UK. Language and Intercultural Communication, 20 (3). pp. 225-239. ISSN 1470-8477

Downloaded from: https://e-space.mmu.ac.uk/624749/

Version: Accepted Version

Publisher: Taylor \& Francis (Routledge)

DOI: https://doi.org/10.1080/14708477.2020.1715995

Please cite the published version 


\title{
Walking along in sticky places: post-humanist and affective insights from a reflective account of two young women in Manchester, UK ${ }^{1}$
}

\author{
Khawla Badwan* and Elisha Hall \\ Department of Languages, Information and Communication, Manchester Metropolitan \\ University, Manchester, United Kingdom.
}

\begin{abstract}
This article reports on a reflective account of a walk-along that brought together a researcher and a participant who visited the Curry Mile (Wilmslow Road) in Manchester, UK. It focuses on places, emotions and materiality in intercultural research in order to understand how 'things make people happen' (Kell, 2015, p. 442). Drawing on the interplay of 'post-humanism' (Pennycook, 2018), emotions in 'sticky' places (Ahmed, 2004, 2014; Laketa, 2018), and 'cultural threads and blocks' (Holliday, 2016), this paper explores how decentring intercultural research facilitates new ways of coming together, allows the construction of cultural threads, and enables creative and reflective engagement.
\end{abstract}

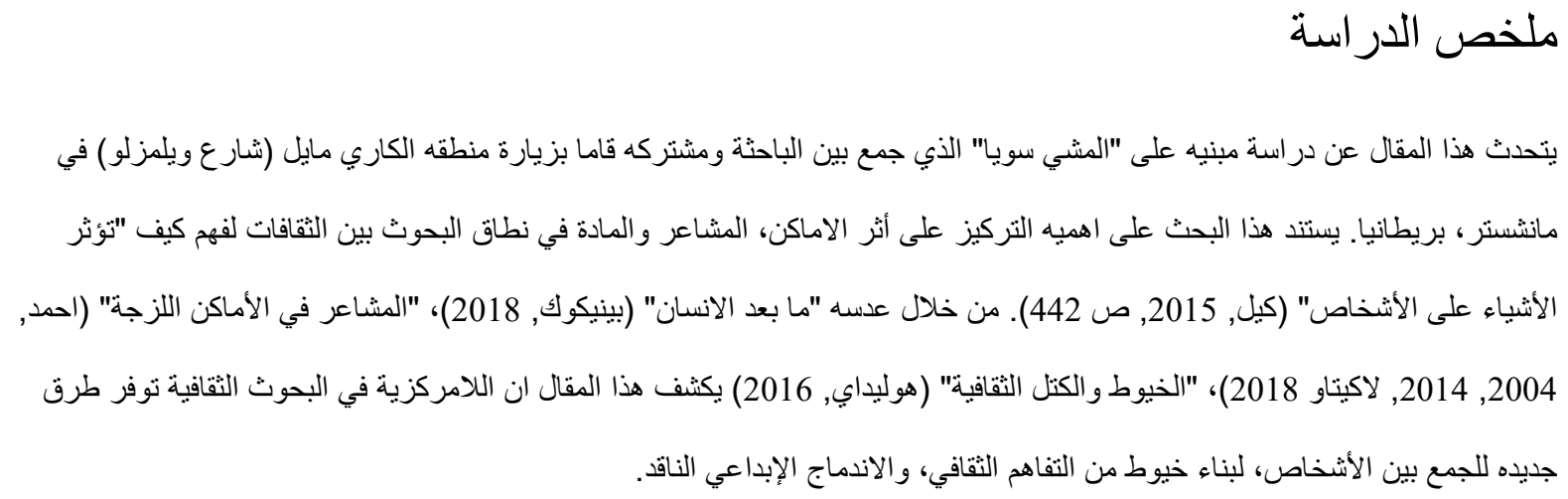

\footnotetext{
${ }^{1}$ This article has been accepted for publication in Language and Intercultural Communication, published by Taylor \& Francis.
} 


\section{Introduction}

Decentred research methodologies need to allow critical spaces in which the unexpected can emerge, and the narratives of subjects can take on a life of their own.

Holliday (2009, p. 147)

By allowing research narratives to take a life of their own, this article explores the affordances of decentring intercultural research. Here, we present three decentring suggestions. The first entails moving away from agenda-driven research and allowing research participants to take a more prominent and collaborative role in guiding the fieldwork. The second suggestion focuses on drawing attention to the ontological engagement and entanglement of intercultural researchers in order to investigate their embedded and embodied experiences as they engage critically, emotionally and reflectively with unexpected intercultural spaces. The third suggestion brings forward the significance of places, objects and emotions while decentring the focus on language and verbal exchanges between researchers and participants. While doing so, we highlight the relevance of post-humanism (Pennycook, 2018) to intercultural research. As such, this article decentres the hierarchy of language, and draws attention to what Barad (2003) refers to as a renewed focus on materiality, in order to understand how 'things make people happen' (Kell, 2015, p. 442).

Directing the attention to places, spaces and objects, we draw on the work of Ahmed (2004, 2014), wherein she explains how the dynamic interplay between humans, objects and spaces invokes emotions that are then attached to objects and spaces to make them 'sticky', and saturated with affect. Such dynamic interactions are crucial to the socio-spatial experiences and practices of individuals. The focus on materiality and emotionality brings to the fore possibilities for exploring the power of place (Butler, 2015) in intercultural research. In addition, it enables research into how objects can be utilised in the creation of cultural threads (Holliday, 2015, 2016). For instance, in one of the examples Holliday (2015) presents, he 
reports on how the presence of 'children things' in a taxi enabled him to establish a cultural thread with a young Chinese driver. These objects opened up an emergent space for talking about childcare and parenting. Commenting on this, Holliday (2016, p. 322) writes,
Instead of looking for blocks, we follow the threads from who we are as people who have something to share to the implications of our circumstances, how we are brought up, where we live... And we may in this way begin to see that we can have something to offer, to contribute in the foreign place where we find ourselves, and perhaps find understandings there that we can apply back to where we come from.

This article reports on a walk-along that brought two individuals together: a British research assistant, Elisha, and an Algerian doctoral student, Samiya. The walk-along, as a research method, aims at exploring spatial experiences in situ while accessing interpretations from the participating walkers (Kusenbach, 2003), and enabling more active (co)production (DeLyser and Sui, 2013). The walk-along was planned to allow Samiya to show Elisha the untellable about why certain spaces in Manchester are significant to her. In return, Elisha found herself in unfamiliar intercultural spaces which she initially approached from a ‘cultural block' (Holliday, 2016) perspective, by virtue of positioning herself as a researcher trying to find out about the spatial experiences of a participant from a different culture. Almost immediately, Elisha's critical engagement with the different places, objects and artefacts invoked emotions and childhood memories that were instrumental to constructing 'cultural threads' (Holliday, 2016), which facilitated understanding and sharing between the two young women. After the walk, Elisha produced a critical reflective account of the walkalong, highlighting critical moments which have taken a life of their own in this article. A moment is a point in Elisha's narrative that describes an event and includes meta-comments, exhibiting critical reflections (c.f. Li, 2011; Author, 2019 on 'moment analysis').

Conceptually, this article draws on a framework that combines spatial approaches to performativity (Butler, 1993, 2015; Gregson \& Rose, 2000) with feminist accounts of affect 
and emotions (Ahmed, 2004), post-humanist approaches to language (Pennycook, 2018), and cultural threads and blocks (Holliday, 2015, 2016). Methodologically, the study demonstrates the potential for go/walk-alongs as a decentring research method in intercultural research. Such a method uncovers how spatialities influence research encounters (Anderson, 2004), an area that remains under-researched in intercultural studies. In addition, go/walk-alongs enable understandings of 'less easily storied' spaces (Holton \& Riley, 2014, p.63), which can be easily overlooked in conventional sit-down interviews.

In what follows, we start by briefly presenting the research context and the circumstances that led to the walk-along reported herein. After that, we discuss the potential of using post-humanism in intercultural studies and the insights that can be generated through researching how individuals inter/intra-act ${ }^{2}$ with spaces, places, objects and artefacts in different or similar ways. Next, we explain how attention to emotions in 'sticky' places is not only aligned with post-humanism but has the potential for opening a window onto the ‘intersubjectivity’ (Holliday \& MacDonald, 2019) of the researcher and the participant to foreground how they collectively construct meanings and report emotions influenced by the politics of research events (Amadasi \& Holliday, 2018). Subsequently, we talk about cultural 'blocks' and 'threads' while arguing for the need to go beyond 'national framings' of cultural blocks. The section that follows presents the methodological aspects of the study before presenting its key moments communicated through multimodal data (text and photos). We conclude by discussing the conceptual and methodological contributions of using walkalongs for decentring intercultural research.

\footnotetext{
2 'intra-' as a prefix is added to 'interact' to foreground 'changes within' (Online Oxford Dictionary, 2020). Section 3 explains how being in contact with objects and places can invoke emotions that move us and affect what the body can do.
} 


\section{Research Context}

This paper comes from a larger project that explores how young people (aged 18-25 years) talk about place-making and belonging in the 'hyper-diverse' (Tasan-Kok et al, 2013) city of Manchester, UK. The project ran between June and August 2019. Since this larger project was funded, we had to produce detailed work packages and outline pre-determined methodological tools and analysis approaches. The process of seeking funding for this project is based on foregrounding the role of the research team and the research agenda, which is the complete opposite of what this article argues for. The larger project utilises online questionnaires completed by 58 university students; in-depth, semi-structured interviews conducted with eight participants; and activity sheets completed by the eight interviewees. Through these research methods, we were able to extract some valuable information about young people's significant places in the city, why they like to be there and how these places contribute to the construction of different types of belonging such as performative belonging, aesthetic belonging, elective belonging and political belonging (Authors, forthcoming). Still, we were trying to open a window on the spatial experiences of students in the city. We, therefore, decided to create a space for a research activity that does not entail producing interview guides. This, coupled with Samiya's offer to show Elisha the symbolic and cultural significance of the Curry Mile, justified the decision to arrange the walk-along activity reported herein.

To access transcendent and reflexive aspects of lived experience in situ (Kusenbach, 2003), Elisha, who had the role of the research assistant in the project, had a six-hour walkalong with Samiya (pseudonym) on 11 September 2019. During this time, Samiya showed Elisha significant places that she frequently visits in Manchester so that she could show her the untellable about why these places create a sense of belonging for Samiya and remind her of places she misses in Algeria. After the walk, and as soon as Elisha returned to the office, 
she wrote down her own reflective account of the walk-along. Elisha was not above, or detached from, the spatial experiences she was researching. Instead, she was enmeshed in the very practices she was researching. This paper is about how places, spaces and artefacts make things happen in intercultural research. It is about how the young women experienced a day together in Manchester, how their own different social positions created different spatial affordances, and how they engaged with places and objects that brought back memories and invoked emotions in 'sticky' places (Ahmed, 2004, 2014). The account features Elisha's reflections on how this experience has led to the emergence of 'cultural threads and blocks' (Holliday, 2016) in a way that deconstructs cultural boundaries and facilitates comingstogether. Her reflective account documents sentiments of nostalgia, memories of childhood, and reflections on wider socio-political tensions.

\section{Post-humanism in Intercultural Communication Research}

Pennycook (2018) explores the potential for post-humanism to construct new understandings of language, humans, place and objects. Barad (2007, p.136) emphasises that post-humanism does not presume the separateness of any-'thing', challenging Latour's (2004, p.446) Great Divides between nature and society, human and non-human. Pennycook (2018) explains that post-humanist thinking breaks from the distinction between interiority and exteriority and enables the understanding of language, subjects and thoughts; not as human properties, but as features distributed across places, people and artefacts. As such, it relocates our assumptions about where social communication and semiotics occur.

Barad (2003) explains that there is a renewed focus on materiality, and a reconsideration of the meaning of what matters (Meillassoux, 2008, p.121). This has led to what Barad (2003, p.808) refers to as 'post-humanist performativity', which 'calls into question the givenness of the differential categories of "human" and "nonhuman", examining the practices through which these differential boundaries are stabilised and destabilised' 
(2003, p.808). Such understanding brings to the fore the importance of recognising the interplay between language, humans and objects. Commenting on this, Pennycook (2018, p.449) asserts that, "there is no longer a world "out there" separate from humans and represented in language but rather a dynamic interrelationship between different materialities'. That is to say, the 'languaging' subject is not separate from the 'languaged' object (MacLure, 2013). As such, language becomes only part of a larger semiotic assemblage (Deleuze, 2007; Harvey et al., 2019).

What is the potential of post-humanism in intercultural studies? First, post-humanism offers an expansive understanding of language, whereby 'linguistic repertoires' are no longer individual and biographical (c.f. Blommaert \& Backus, 2013, p.15). Rather, they are emergent properties that derive from the inter/intra-action between people, artefacts and spaces (Pennycook, 2018). Post-humanism enables discussions of how 'things make people happen' (Kell, 2015, p.442), which is an important consideration in intercultural research. That is to say, post-humanism has the potential of offering new insights into researching culture, and into how individuals interact and intra-act with spaces, places and artefacts in different or similar ways. Second, post-humanism allows intercultural communication researchers to open a window onto emergent, un-tellable experiences produced by and within spaces and materiality. For instance, in this project Samiya told Elisha that the Curry Mile in Manchester creates a temporary sense of belonging for her, yet the Curry Mile was a 'less easily storied' space (Holton \& Riley, 2014, p.63). It was through being in these spaces and inter/intra-acting with objects, signs and artefacts that Elisha was able to understand what Samiya could not tell in words. Third, post-humanism opens up spaces for researching what Holliday and MacDonald (2019) refer to as 'intersubjectivity' in intercultural research. We have noticed how both Elisha and Samiya interacted with spaces and artefacts in one of Samiya's significant places. This interaction generated untellable emotions, not only for 
Samiya but also for Elisha, who started to think of childhood memories and to reflect on her social positioning in the world. This is an example of how intercultural researchers cannot write about their research without reflecting on their 'own histories, social and cultural locations as well as subjectivities and values' (Merrill \& West, 2009, p. 5). Fourth, posthumanism enables researching spatial performativity and emotions in 'sticky' places: factors that can indeed go unnoticed unless attention is paid to the interplay of place, language and objects, as the next section demonstrates.

\section{Emotions in Sticky Places}

What moves us, what makes us feel, is also that which holds us in place, or gives us a dwelling place. Hence movement does not cut the body off from the 'where' of its inhabitance, but connects bodies to other bodies: attachment takes place through movement, through being moved by the proximity of others.

(Ahmed, 2014, p.11)

In Cultural Politics of Emotions, Ahmed (2014) talks about emotions, affect ${ }^{3}$ and objects and how they are linked to how individuals inhabit place. She explores how emotions move, how objects become sticky and saturated with affect, and how objects become sites of personal and social tensions. The intensification of emotion and affect in everyday spatial practices are 'bound up with how we inhabit the world, how we live in relationship to the surfaces, bodies and objects that make up our dwelling places' (Ahmed, 2004, p.27). Here, the body is not a static, neutral surface, but a medium through which power operates (Butler, 1993). Rather than asking what emotions are in the body, Ahmed (2004) considers what they do. She argues that when emotions are invoked as a result of contact with objects, they are "not simply "in" the subject or the object' (Ahmed, 2014, p.6). The interaction between and within the human and the non-human, Ahmed (2014) argues, produces emotions that shape what bodies do,

\footnotetext{
${ }^{3}$ Feminist researchers use the terms 'emotions' and 'affect' differently. Ahmed $(2004,2014)$ does not explicitly distinguish between the two terms. Some argue that emotion are 'sociological expressions of feelings whereas affect is more firmly rooted in biology and in our physical response to feelings' (Gorton, 2007, p. 334). When Ahmed (2014) discusses the 'affective turn' in social sciences, she draws on Hardt's (2007) distinction, suggesting that affect refers to the body and mind, reason and passion (Ahmed, 2014, p. 206).
} 
stick to objects and bodies, and move around, circulating variations in intensities of feelings. Such variations are fundamental to guiding young peoples' everyday socio-spatial practices (Laketa, 2018). To mark the dynamic locality of emotions within/in/between bodies and objects and to emphasise how emotions move within and affect what the body can do, we use the prefixes 'inter' and 'intra' in inter/intra-act' in this article.

Emotions, argues Ahmed (2014), show us the world, an idea which led her to argue for a 'feel our way' approach, as a form of cultural politics and world making. She presents an example of how a white racist subject can experience intensities of emotions (fear, hate, disgust, pain) upon encountering a racial other (2014, p.194). This intensification entails moving away from the other or moving towards the other in an act of violence before moving away. This moment of contact is shaped by histories; these histories create emotions, which influence what bodies can do.

In addition, place and the performative power of place (Butler, 2015) is an underresearched theme in intercultural studies. Place is crucial when researching identity construction and spatial performativity. We are reminded by Cloke and colleagues (2008, p.245) that, 'places are made meaningful only by the embodied and emotional interactions'. This aligns with post-humanist approaches that perceive the individual as embodied and embedded in place and materiality. Some places are sticky; defined by Laketa (2018, p.179) as 'a performative embodied space saturated with affect'. Because individuals perform multiple identities depending on the where, when, and whom of communication, adding place to the mix creates space for researching how individuals interact and intra-act with place, objects and artefacts through language, 'small cultures' (Holliday, 1999) and emotions.

Intercultural studies can benefit from researching emotions in sticky places for two reasons. First, emotions have a significant influence on what bodies can do, how individuals 
behave in certain places and how they 'feel their ways' (Ahmed, 2004). It creates room for incorporating intersubjectivities where the emotions of both the researcher and the participant are considered. Second, attention to emotions and the interplay of human-human, humannonhuman relationships allows intercultural researchers to explore individual encounters and experiences from a more expansive post-humanist perspective.

\section{Researching Culture: Blocks and Threads}

Intercultural studies have witnessed a major paradigm shift from positivism to postmodernism (Holliday \& MacDonald, 2019). While positivism perceives the world as an objectively describable reality (Martindale, 1960, p.53), postmodernism critiques grand narratives of national and ethnic cultures, arguing that they are socially constructed (Berger \& Luckmann 1979), 'imagined' (Anderson, 2006) and 'liquid' (Bauman, 2000). Beck and Sznaider (2006, p.3) explain that the mapping of one-nation, one-culture and one language is ideologically motivated by a methodological nationalism, which stems from the 19th century European grand narrative of the nation-state. To this end, Holliday and MacDonald (2019, p.8) caution against the neo-racist implications of using nationality as a basis for cultural groupings. Instead, they argue, 'nationality is only one of many variables' $(2019, \mathrm{p} .8)$ and encourage researchers not to look at nationality as a defining feature and to allow participants to accept or reject the role of emerging variables, or what we prefer to call 'factors', such as nationality, religious affiliation, etc. in the interpretations of their intercultural encounters.

Holliday (2016) explains that breaking from positivism and essentialism seems to have created softer and more radical versions, with two types of thinking captured in the concepts 'cultural blocks' and 'cultural threads'. Holliday (2016) discusses the notion of 'cultural blocks' as a soft version of non-essentialism, which entails thinking about cultural differences as 'blocks' framed around uncrossable national cultures. What differentiates this way of thinking from essentialism is that it acknowledges the complexity and diversity within 
separate cultures. 'Cultural threads', on the other hand, is a concept framed around crossing cultural boundaries and creating a common ground for sharing. It is a more radical version of non-essentialism, less straightforward and perhaps more difficult to conceptualise (Holliday, 2016). Its premise is based on looking for commonalities that 'provide us with the basis to engage creatively with culture wherever we find it, and with each other, wherever we find ourselves' (Holliday 2016, p.321).

Nevertheless, we note that the 'cultural blocks' concept is mainly framed around uncrossable national blocks. It stems from thinking about 'cultural difference in terms of blocks [and] maintains the notion of national cultures as separate experiences and as the prime units of cultural identity' (Holliday, 2016, p.319). Aligned with more recent work by Holliday and MacDonald (2019), wherein they critique the over-dependence on 'national framings' in intercultural studies, we draw on the 'intersectionality' (Davis, 2008) of factors such as ethnicity, gender, nationality, religious affiliations and social class. We argue that such factors intertwine, in complex and nuanced ways, with cultural identity and that they each have the capacity to construct cultural blocks. Therefore, we would like to extend the concept of 'cultural blocks' to include factors other than national framings of cultural differences.

\section{The Study}

The data this study comes from a reflective account of a six-hour walk-along written by Elisha, who met Samiya a month earlier to interview her about her experiences of living in Manchester. The interview lasted for over 2.5 hours. At the end of the interview, Samiya offered to take Elisha to the Curry Mile to show her the places she frequently visits. Samiya explained that she goes to the Curry Mile during the daytime only. Because of this, the walkalong started at $11 \mathrm{am}$ and finished at $5 \mathrm{pm}$. Samiya mentioned that she frequently goes to parks, either Whitworth Park or Platt Fields Park, both of which mark the parameters of the Curry Mile. Elisha and Samiya agreed to meet at Whitworth Park, walk along the Curry Mile 
(Wilmslow Road) to Platt Fields Park and return to Whitworth Park, covering the opposite side of the Curry Mile upon their return. The allocation of six hours to cover a walking route that would usually take 15 minutes (according to most GPS routing apps), guarantees a period of 'adequate coverage' (Atkinson \& Hamersley, 2007, p.37).

\subsection{Reflective Accounts and the 'Problematic Privilege'}

Reflective accounts present the intersection of narration and reflection (Hampl, 1999, p.33), which can be used to contextualise and illuminate important socio-political issues and questions (Vandrick, 2009, p.10). They offer the possibility to access 'another kind of truth' obtained from 'narratives, stories, and first-person viewpoints, which people use to construct their realities and interpret their experiences' (Casanave \& Vandrick, 2003, p.2). As such, they create spaces for documenting emotions, observations and interpretations, while trying to produce 'a tale worth telling' (Carless, 2012, p.2). The use of this research tool is aligned with scholarly research in feminist and cultural studies which epistemologically insist on the relevance of the 'everyday' not only as an object of inquiry but as a source of authority (Willard-Traub, 2006, p.425).

In addition, reflective writers often engage with their own 'problematic privilege' (Vandrick, 2009; Stanley, 2018; Piggin, 2018). They utilise their critical entanglement and engagement to develop analytic, self-critical writings, which are not only connected to larger socio-cultural contexts but are also reflective of their privileged positions. In this study, Elisha engages critically with her 'problematic privilege'. Doing so results in a temporary emergence of 'cultural blocks', framed around ethnicity, gender roles, and religious affiliations. These 'blocks' momentarily explained to Elisha how she leads a different life, with different positions and affordances. Yet, her critical and reflective engagement with these positions led to the emergence of cultural threads. As such, the study responds to Holliday and MacDonald's (2019, p.14) call for paying attention to intersubjectivity in 
intercultural studies in order to 'see the liquid nature of the intercultural that cuts across imagined solid culture boundaries'.

\subsection{Why the Curry Mile?}

The Curry Mile is a nickname for part of Wilmslow Road in south Manchester. It earned its title because of the large number of curry houses and takeaway shops that stand side-by-side on a mile-long stretch of Wilmslow Road. The Curry Mile now hosts shisha bars, dessert shops, and Middle-Eastern, Afghani, Persian, and South Asian restaurants, among many other shops that sell clothes and cultural artefacts.

Elisha decided to visit the Curry Mile because it was mentioned by the eight research participants, either because it was a place they frequently visit - as in the case of Samiya, for whom the place holds some cultural and symbolic significance - or as a place they try to avoid. Those who avoided the place spoke about feeling uncomfortable with its dense ethnic diversity and reported feelings of being unsafe. Intrigued by these polarised views, Elisha, who lived most of her life between Sheffield and Leeds and had not been to this part of Manchester before, was curious to explore the spatial experiences of being in the Curry Mile.

We have decided not to anonymise the name of the Curry Mile, where the study took place. We agree with Guenther (2009, pp. 418-419) that concealing names would result in lost meanings because names hold and reflect specific histories, which 'even the cleverest pseudonyms would be unlikely to capture'. The Curry Mile is a 'sticky place' (Ahmed, 2014), filled with histories and emotions. Providing a pseudonym neutralises the place and removes its histories, its stickiness. Elisha also preferred not to use a pseudonym which she perceived as silencing (Guenther, 2009, p.414). However, Samiya was assigned a pseudonym since she agreed to take part in the study based on the promise of anonymity, which became an ethical requirement. The next section introduces the two young women. 


\subsection{Introducing the Walkers}

In her reflective account, Elisha produces two profiles: one for herself and the other for the research participant. The profiles appear in Table 1 below:

\begin{tabular}{|l|l|}
\hline Elisha & Samiya \\
Age: 26 & Age: 25 \\
Gender: Woman & Gender: Woman \\
Socioeconomic Status: Working-Class & Socioeconomic Status: Middle-Class \\
Education: BA (Hons) Sociology & Education: Doctoral student \\
Religion: Atheist & Religion: Muslim [visibly noticed as she \\
Ethnicity: White-British & wears a headscarf] \\
& Ethnicity: Arab \\
\hline Table 1: Introducing the walkers & \\
\hline
\end{tabular}

While the above descriptions reduce the two women into certain identity categories, Elisha's account aims to probe the complicated intersection of gender-ethnicity-age-class- religion, embodied by her individual experiences and those of Samiya. As such, this intersectionality has created 'a gathering place for open-ended investigations of the overlapping and conflicting dynamics of race, gender, class, sexuality, nation, and other inequalities' (Cho, Crenshaw \& McCall, 2013, p.788).

\section{Findings and Discussion}

\section{Moment (1): 'The surrounding area reminds me of the town I grew up in'}

This walk-along journey starts from a 'cultural block' (Holliday, 2016) perspective: a researcher aiming to find out about the spatial experiences of a participant from a different culture in a 'sticky place' (Ahmed, 2004) that hosts cultural artefacts from the Middle East, South Asia and Afghanistan. Even before the walk-along starts, Elisha experiences a dramatic turn of events as she finds herself waiting for Samiya in a place that invoked childhood memories and reflections on social class: 
I arrived early to observe the area. Whitworth Park is situated next to Whitworth Art Gallery... Oddly, the surrounding area reminds me of the town I grew up in - minus the Art Gallery. I can see structures that are unequivocally enmeshed with working-class culture - stores like Poundland, a pub, terrace houses - even the park itself. However, the oddity - for me - comes in the people these structures facilitate. When you grow up in the North, in a working-class town, there are distinctions which appear to be inalienable - the way you walk, talk, dress etc. - they are symbolic of class and geography, but in the heart of cosmopolitan Manchester, the distinctions of the structures that surround me are not emblematic of the people that inhabit this place. For a moment, I wonder if this is influenced by this place's proximity to the Gallery whether the cultural capital of that institution has repurposed an area that seems to be foregrounded by working-class heritage; therefore, it feels like the socioeconomic make-up of the population can no longer be isolated to traditional class geographies.

Elisha is in the park as a researcher and observer. However, the park and its surroundings, for Elisha, are saturated with working class histories and ideologies. It has become a sticky place that invokes childhood memories and social class reflections. The familiarity of the place makes Elisha remember where she grew up. Yet, she notices that the place, with its working class heritage, is no longer exclusively accommodating working-class individuals. The place's current proximity to the Art Gallery and universities has somehow repurposed its use. This moment is crucial in Elisha's account since subsequent moments continue to invoke childhood memories and class reflections. They also demonstrate the human, non-human inter/intra-action and show how Elisha and Samiya were 'feeling their way' (Ahmed, 2014) while walking along the Curry Mile.

\section{Moment (2): 'I was overcome by an overwhelming sense of contentment-of peace'}

After Samyia and Elisha met, Samiya took Elisha to a swing, secluded and located in what feels like a vantage point from which they can observe the general activities of the park. They approached the swing and started swinging back and forth. Fig. 1 shows a photo of the swing set. 


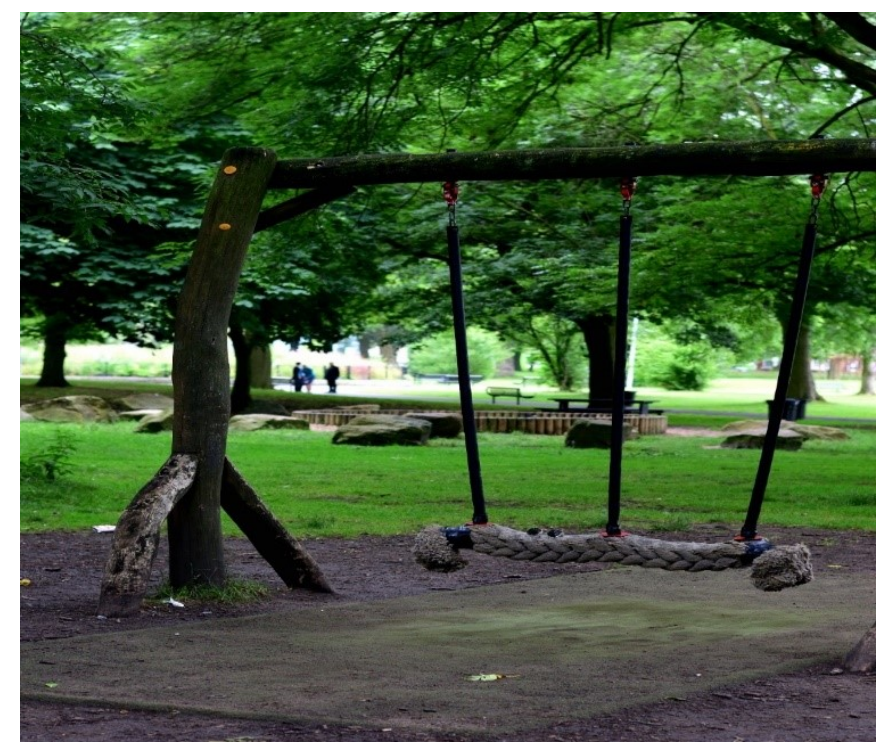

Figure 1: The Swing-set in the park

Elisha writes:

Sat there, suspended in the air, under a canopy of trees, I was overcome by an overwhelming sense of contentment - of peace. At once, I found this inherently paradoxical, to be sat with someone I had interviewed once, in a place I am unfamiliar with and feel a level of contentment that you would ordinarily experience with a person you had known intimately for years. As I continued to quietly ruminate, I heard a school bell siren to the left of us; the school is situated within the park and, offset from the swings, we were able to see children being ushered back to class after their morning break. I realised then, that the contentment I was experiencing was temporally attached to the ritual of childhood - that contentment was in fact rooted in the familiarity of a practice I had once done during my formative years - and when I engaged in it now, it appeased me - the visceral nostalgia of it - for a few moments you're a child again. I began to understand why so many participants listed parks as places they frequent, there is a safety in that familiarity - a sense that everything will be okay, just as it was in childhood.

Elisha also talks about what the park means to Samiya:

In her interview, Samiya spoke of playing on the swing with an Indian friend and now, she recollects a recent experience with a young BritishPakistani woman she met whilst volunteering. Here, on the swing set, this woman feels that she belongs; I believe her sense of belonging is garnered - like my own in that moment - by the familiarity of the practices she experienced during her childhood. Samiya has not used a swing since being a young girl, in Algeria.

The swing is sticky with memories, emotions and nostalgia. It has become stickier with the connection it has created between Elisha and Samiya. The two young women are both 
embodied and embedded in the materiality of the park. The boundaries between the 'human' and the 'nonhuman' are destabilised (Barad, 2003). This materiality matters (Meillassoux, 2008), as it affects the 'spatial performativity' (Barad, 2003) of the two young women. They are both relaxed and free. For a short period, Elisha is no longer a researcher and Samiya is no longer a participant.

What is noticeable in this moment is the potential for objects and materiality to create cultural threads. When Elisha writes, 'I believe her sense of belonging is garnered - like my own in that moment - by the familiarity of the practices she experienced during her childhood', she talks about a strong cultural thread that was created by being on the swing together. This moment shows how objects and emotions in sticky places facilitate the creation of cultural threads, familiarity and coming-together.

\section{Moment (3): 'She draws my attention to a Harissa tub'}

Elisha and Samiya took shelter from the rain inside the Whitworth Art Gallery where they had coffee and chatted about how the area surrounding the gallery, which also marks the start of the Curry Mile, appears to be 'cosmopolitan'. They are then attracted to another object, sitting on their table:

Samiya draws my attention to - what I termed 'cultural artefacts' - a Harissa tub that had been repurposed as a sugar pot; she explained that in her country, Harissa is a key ingredient in a student meal oven baked Hummus, topped with Harissa and served with baguette. However, to myself it bore no significance and this is perhaps how cultural distinctions go unrecognised by people that are unaware of their purpose.

The harissa tub moves Samiya, makes her feel the connection to her home in Algeria and invokes memories of hummus sandwiches topped with harissa. In this moment, Elisha does not share the same emotions towards the object. Elisha was simply looking at what appeared to be a 'sugar pot' that bears 'no significance' to herself. Still, she reflects on this moment by 
wondering how many cultural artefacts can go unrecognised when people are not aware of their significance. This highlights the usefulness of walk-alongs in developing numerous interpretations of materiality in urban spaces, a way of exploring alternative meanings of individuals' spatial experiences.

\section{Moment (4): 'She turns to me and says, "I don't feel like I am in Britain here"!'}

As soon as they started walking in the Curry Mile, Samiya reports feelings of familiarity in the place. She did not feel like she was in Britain, which invoked feelings of being in Algeria. In this moment, Elisha reports a different view:

I wouldn't consider anything that exists here as being uncommon to Britain or being British - if British and Britain aren't being used as synonyms for White. However, there appears to be proclivity for these establishments to be isolated to areas that fall beyond the parameters of the 'centre' and thus, they are beyond the most commonly populated and visually consumed parts of the city. I grew up in a town that was multicultural and these structures are familiar - as is there geographic placement. What is uncommon, in my experience, is their abundance; there are a myriad of food restaurants, butchers, grocers, barbers, solicitors, shisha bars and mosques; all of which specialise and cater to the nuance of cultures originating across the MiddleEast. These - as in my hometown - appear to be in previously White working-class areas; where any person of colour would have once been a minority, the reverse is now true. I assume that this is a result of White-flight during the 1970s epoch of de-industrialisation and the affordability/ availability of shops to rent.

In this moment, Elisha critically engages with wider social and political aspects. Her upbringing is once again crucial to her understanding of the world. This new place continues to bring back memories from Elisha's childhood. Interestingly, the place is familiar to both women, but in different ways. This moment highlights the power of place (Butler, 2015) and how its meaning is created only by individuals' embodied and emotional interactions (Cloke et al., 2008).

This moment seems to have two crucial points. The first is related to emotionality. For Elisha, the architecture of the place and its working-class heritage invoked emotions and 
memories of the town where she grew up. For Samiya, the Middle-Eastern artefacts, stores and restaurants made her feel as if she was in Algeria. This is a place saturated with histories and emotions for both of them. The second point is referencing whiteness in this sticky place. We discussed this together to address the question, 'but why is it relevant that it was once white?'. Elisha reflected on this by explaining that experiences of place can be indeed linked to ethnicity - which could be a cultural block. Signifying whiteness alludes to spatial power dynamics and historical ownership of place, yet the multicultural feel of the place acted as a cultural thread, based on notions of familiarity, which enabled both Elisha and Samiya to connect to the place. This brings to the fore the usefulness of post-humanist approaches (Pennycook, 2018) to understanding spatial experiences in intercultural studies.

\section{Moment (5): 'There is always an uncertainty in that which cannot be understood'}

Elisha stops to read a sign (Fig. 2) and she writes,

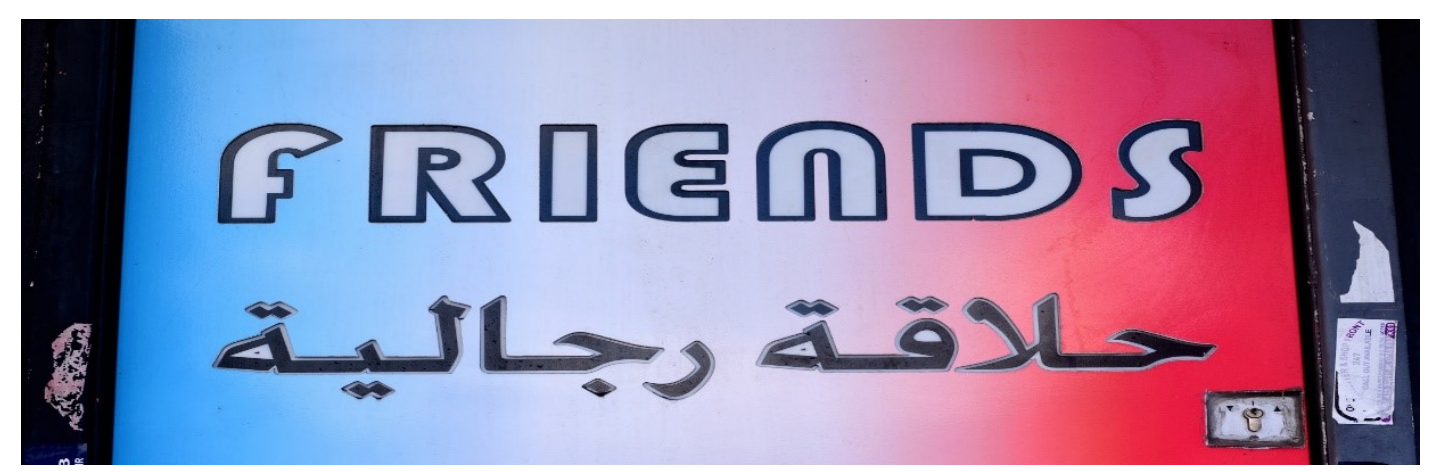

Figure 2: A Gents' Hairdresser in the Curry Mile

I am suddenly compelled to notice the ubiquitous presence of Arabic and other languages that I am unable to recognise (nor is Samyia). Some have an English counterpart, others do not and I cannot derive any significance from them. There is always an uncertainty in that which cannot be understood. I 
think about the current political climate and how difference is being weaponised by far-right nationalists. I wonder if the use of the term 'Friends' is intentional - to disarm someone that perceives difference as a threat... For me, a White-British, cis-gendered woman, it is rare that I do not see myself or my culture represented. As I stand back, this sign - I quickly realise - is affixed to a 'Gents' Hairdressers'; however, this doesn't reduce the term's impact for me, in a sense it gives substance to thought - someone's livelihood is dependent on the success of this store and that seems to fortify my initial thoughts.

Elisha explains how the presence of many languages created a sense of uncertainty. She then explains how far-right discourses demonise difference, nurture 'linguistic hostility' (Piller, 2016) and promote 'ethnolinguistic nationalism' (Cameron, 2013). Yet, for Elisha the word 'Friends' was there to 'disarm someone that perceives difference as a threat'. Without seeking help from Samiya and by relying on wider semiotic assemblage (signs, photos, and the façade), Elisha was able to understand that the Arabic sign means 'Gents' Hairdressers'. This is an example of how individuals' linguistic repertoires can indeed be 'emergent properties that derive from the interaction between people, artefacts and spaces' (Pennycook, 2018, p.454).

\section{Moment (6): 'I don't understand the semantics at play here'}

Samiya takes Elisha to her favourite shop and explains that she was initially attracted to the shop because of its façade (Fig. 3). 


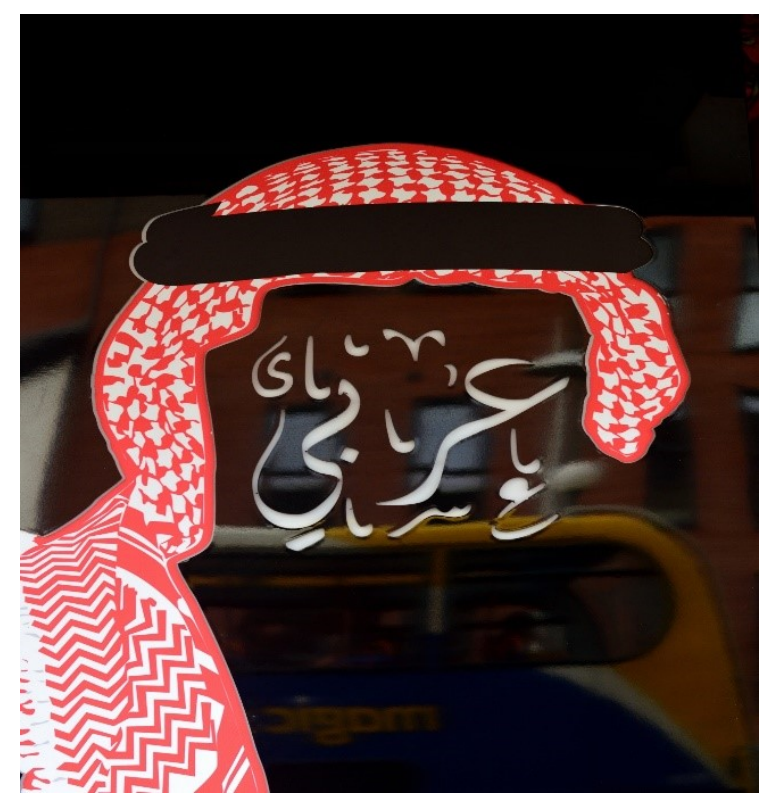

Figure 3: The pull towards familiarity

Commenting on the shop front, Elisha writes,

I don't understand the semantics at play here, but I do recognise that its use of semiotic signals its intended demographic. As we enter, I ask Samiya to highlight any objects that are significant - whilst doing this I recognise that there are objects and products in this store that are commonplace in my own cultural experience- teapots (see Fig. 4), spices (see Fig. 5) etc. - however, I sense that it is culture that distinguishes how they are used. The sign affixed to the façade seems to affirm that notion, and for myself, it generates a cultural distinction. 


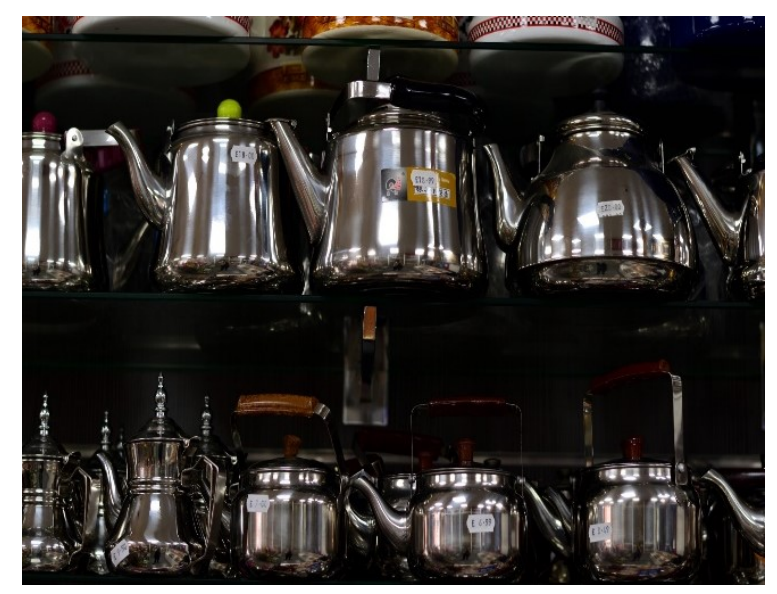

Figure 4: Teapots

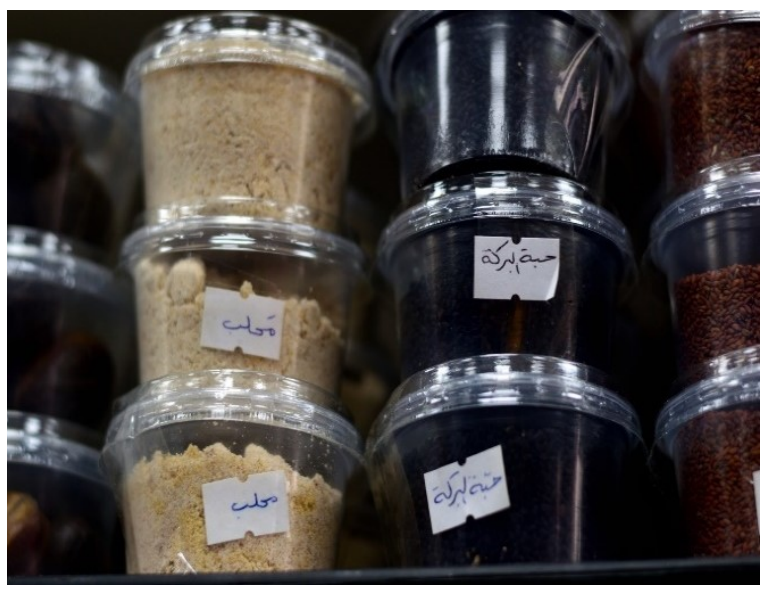

Figure 5: Spices with labels in handwritten Arabic

Elisha reacts to the objects in figures 4 and 5 differently:

I find myself looking at the teapots, they are slightly different in appearance to those that I can recall using and I feel as though these would be used in a way that differs from the way that I have come to use them; and so, I feel as though I wouldn't use it unless I understood the context in which it is traditionally used - the practice and its cultural context. However, I don't feel this way about spices - irrespective of my inability to decipher Arabic - I can distinguish the spices through aroma; the barrier I felt between one object and another is palpably different and this is, perhaps, due to the extent in which certain cultural items have been commodified and assigned with capital in British supermarkets. Here, I can't help but feel that that process is appropriation and that there is a fine line between accessibility and the former.

We highlighted the word 'feel/felt' in the above extract and noticed the relevance of 'emotions and affect' (Ahmed, 2004, 2014). In her intercultural contact with these objects, Elisha relies 
heavily on emotions, which in return, impact on how she relates to the different objects.

Indeed, Elisha is 'feeling her way' (Ahmed, 2004, 2014) and this agrees with Ahmed's (2004)

observations that the intensification of emotions in everyday spatial practices are bound to 'how we live in relationship to the surfaces, bodies and objects that make up our dwelling places' (Ahmed, 2004, p.27). Elisha seems to approach the teapots from a 'cultural block' perspective; she appreciates them and understands that they are used differently in different cultures. However, she is not able to relate to them and not sure if she can use them. On the other hand, Elisha adopts a 'cultural thread' perspective when looking at the spices even though she could not read the Arabic labels. She was able to use her sense of smell to identify the spices which 'smell familiar'. Through a post-humanist perspective, we are able to comment on the human, non-human inter/intra-action while featuring the power of emotions in this intercultural contact.

\section{Moment (7): 'I have the privilege of preference'}

During their walk-along, Elisha was trying to establish what it feels like to be in Samiya's position in the world. It seems that the cultural threads they had established during this walk have produced a good intercultural relationship. Commenting on this, Elisha writes,
During this conversation, I am forced to recognise the intersectional challenge Samiya faces. She feels free to go where she pleases in the city. However, this street accommodates a large part of her cultural identity - commodities, communities and religion. This does in some way circumscribe a large aspect of her identity to this geographic location. Unlike myself, I am not dependent on a singular location to accommodate my identity. I have the privilege of preference. On this street her gender, religion, clothing style, and ethnicity appear to prevent her from going into a bar. Beyond this street, I wonder how and if all these factors intersect to prevent that experience in more insidious ways.

In this moment Elisha critically engages with her 'problematic privilege' (Stanley, 2018; Piggin, 2018). She speaks of her 'privilege of preference', and how it facilitates different life affordances. Her reflections confirm the need to go beyond national framings when theorising 
cultural blocks and indicate the importance of intersectionality (ethnicity, gender, religion) in intercultural studies. Elisha is also critically engaged with wider socio-political aspects of living in the city.

\section{Conclusion}

This walk-along has enabled the emergence of critical spaces, which have highlighted the significance of the inter/intra-action with different objects, places and artefacts in a way that demonstrates the potential for using post-humanist and affective lenses in intercultural research. Drawing on the interplay of 'post-humanism' (Pennycook, 2018), emotions in 'sticky’ places (Ahmed 2004, 2014, Laketa, 2018), and 'cultural threads and blocks' (Holliday, 2016), this paper explores the spatial experiences of Elisha and Samiya in situ. At the same time, it demonstrates the usefulness of decentring research by moving away from interview guides, allowing participants to take a prominent role in choosing where the 'fieldwork' is, and drawing attention to affective and post-humanist lenses, instead of the common reliance on language.

Allowing Samiya to set the plan for the day has indeed placed Elisha in unexpected critical intercultural spaces with which she engaged emotionally, critically, creatively, positively, socially and politically. Such embodied and embedded experiences were crucial to the development of cultural threads that facilitated the coming-together between the two young women. At the end of the day, not only did Elisha understand why The Curry Mile was a significant place for Samiya, but she also became more aware of her social positionality and privilege.

Revisiting Holliday's (2009) quotation with which we opened this paper, we reiterate the value of decentring research which has allowed this paper to happen. Nonetheless, we also acknowledge the structural challenges of conducting decentred research at a time when 
academic funding bids are based on detailed descriptions of research agendas, work packages, timelines, pre-designed research tools and analysis plans. We had to go through the same process to seek funding for the larger project. Yet, we tried to create room for this research to explore the uncharted territories of decentred intercultural research. This research has informed us of the affordances of walking into 'the field' without pre-prepared notes and has uncovered the opportunities of allowing research narratives to take a life on their own.

\section{Acknowledgments}

We would like to acknowledge the contribution of Lou Harvey, Samantha Wilkinson, two anonymous reviewers and the editor in shaping the development of this paper and thank them with gratitude. Thanks are also due to Samiya for accepting to lead on this walk-along, which ultimately allowed this paper to happen.

\section{Funding}

This project was funded by Manchester Metropolitan University, Research Accelerator Grant.

\section{References}

Ahmed, S. (2004). The Cultural Politics of Emotion. London: Routledge.

Ahmed, S. (2014). The Cultural Politics of Emotion. $2^{\text {nd }}$ Edition. London: Routledge.

Amadasi, S. \& Holliday, A. (2018). 'I already have a culture': Negotiating competing grand and personal narratives in interview conversations with new study abroad arrivals. Language and Intercultural Communication, 18(12), 241-56.

Anderson, B. (2006). Imagined Communities, 2nd edn. London: Verso.

Anderson, J. (2004). Talking whilst walking: a geographical archaeology of knowledge. Area, 36, 254-61. 
Atkinson, P. \& Hammersley, M. (2007). Ethnography: Principles in Practice. London: Routledge.

Barad, K. (2003). Posthumanist performativity: Toward an understanding of how matter comes to matter. Signs: Journal of Women in Culture and Society, 28, 801-31.

Barad, K. (2007). Meeting the Universe Halfway: Quantum Physics and the Entanglement of Matter and Meaning. Durham: Duke University Press.

Bauman, Z. (2000). Liquid Modernity. Cambridge: Polity.

Beck, U. \& Sznaider, N. (2006). 'Unpacking cosmopolitanism for the social sciences: A research agenda. British Journal of Sociology, 57 (1), 1-23.

Berger, P. \& Luckmann, T.(1979). The Social Construction of Reality. London: Penguin.

Blommaert, J. \& Backus, A. (2013). 'Super diverse repertoires and the individual' in I. deSaint-Georges and J-J. Weber (eds).Multilingualism and Multimodality: Current Challenges for Educational Studies (pp. 11-32). Boston: Sense Publishers.

Butler, J. (1993). Bodies that Matter: On the Discursive Limits of 'Sex'”. New York: Routledge.

Butler, J. (2015). Notes Toward a Performative Theory of Assembly. Harvard: Harvard University Press.

Cameron, D. (2013). The one, the many and the Other: Representing multi- and monolingualism in post-9/11 verbal hygiene. Critical Multilingualism Studies, 1(2), 59-77.

Carless, D. (2012). Negotiating sexuality and masculinity in school sport: An autoethnography. Sport, Education and Society, 17(5), 605-625. 
Casanave, C. and Vandrick, S. (2003). Writing for Scholarly Publications. Mahwah: Lawrence Erlbaum Associates.

Cho, S., Crenshaw, K. W., \& McCall, L. (2013). Toward a field of intersectionality studies: Theory, applications, and praxis. Signs - Journal of Women in Culture and Society, 38(4), $785-810$.

Cloke P, May, J. \& Johnsen, S. (2008). Performativity and affect in the homeless city. Environment and Planning D: Society and Space 26(2): 241-263.

Davis, K. (2008). Intersectionality as Buzzword: A Sociology of Science Perspective on What Makes a Feminist Theory Successful. Feminist Theory, 9(1), 67-85.

Deleuze, G. (2007). Eight years later: 1980 interview. In Two Regimes of Madness: Texts and Interviews 1975-1995 (Rev. ed.). (A. Hodges \& M. Taormina, Trans.) (pp. 175-180). Paris: Semiotext(e).

DeLyser, D. and Sui, D. (2013). Crossing the qualitative-quantitative divide II: inventive approaches to big data, mobile methods, and rhythmanalysis. Progress in Human Geography 37, 293-305.

Gorton, K. (2007). Theorising emotion and affect. Feminist Theory, 8(3), 333-348.

Gregson, N. \& Rose, G. (2000). Taking Butler elsewhere: Performativities, spatialities and subjectivities. Environment and Planning D: Society and Space, 18(4), 433-452.

Guenther, K. (2009). The politics of names: rethinking the methodological and ethical significance of naming people, organizations, and places. Qualitative Research 9(4), 411421.

Hampl, P. (1999). I Could Tell You Stories: Sojourns in the Land of Memory. Norton: New York. 
Hardt, M. (2007), 'Foreword: What Affects are Good For'. In P. Clough (ed.). The Affective

Turn. Durham: Duke University Press.

Harvey, L., McCormick, B. \& Vanden, K. (2019).Becoming at the boundaries of language:

Dramatic Enquiry for intercultural learning in UK higher education, Language and Intercultural Communication.

Holliday, A. (1999). Small cultures. Applied Linguistics, 20(2), 237-264.

Holliday, A. (2009). The role of culture in English language education: Key challenges. Language and Intercultural Communication, 9(3), 144-155.

Holliday, A. (2015). Talking about cultural difference - Blocks and threads. Blog. Retrieved from http://adrianholliday.com/blog

Holliday, A. (2016). Difference and awareness in cultural travel: negotiating blocks and threads. Language and Intercultural Communication, 16(3), 318-331.

Holliday, A. \& MacDonald, M. (2019). Researching the intercultural: Intersubjectivity and the problem with postpositivism. Applied Linguistics, 1-20.

Holton, M. \& Riley, M. (2014). Talking on the move: place-based interviewing with undergraduate students. Area, 46(1), 59-65.

Kell, C. (2015). Making people happen: Materiality and movement in meaning making trajectories. Social Semiotics, 25, 423-45.

Kusenbach, M. (2003). Street phenomenology: The go-along as ethnographic research tool. Ethnography, 4(3), 455-485.

Laketa, S. (2018). Between "this" side and "that" side: on performativity, youth identities and “sticky” spaces. Environment and Planning D: Society and Space. 36(1),178-196. 
Latour, B. (2004). Politics of Nature: How to Bring the Sciences into Democracy. Harvard University Press.

Li, Wei. (2011). Moment analysis and translanguaging space: Discursive construction of identities by multilingual Chinese youth in Britain. Journal of Pragmatics. 43,1222-1235.

MacLure, M. (2013). Researching without representation? Language and materiality in postqualitative methodology. International Journal of Qualitative Studies in Education, 26(6), $658-667$.

Martindale, D. (1960). The Nature and Types of Sociological Theory. London: Routledge.

Meillassoux, Q. (2008). After Finitude: An Essay on the Necessity of Contingency (R.

Brassier, Trans.). London: Bloomsbury.

Merrill, B. \& West, L. (2009). Using Biographical Methods in Social Research. London: Sage.

Pennycook, A. (2018). Posthumanist Applied Linguistics. Applied Linguistics, 39(4), 445461.

Piggin, G. (2018). Performing problematic privilege in Japan. In P. Stanley and G. Vass (eds.). Questions of Culture in Autoethnography. London: Routledge.

Piller, I. (2016). Linguistic Diversity and Social Justice. Oxford: Oxford University Press.

Stanley, P. \& Vass, G. (2018). On the difficulties of writing about culture in autoethnography. In P. Stanley and G. Vass (eds.). Questions of Culture in Autoethnography. London: Routledge.

Tasan-Kok, T., van Kempen, R., Raco, M. and Bolt, G. (2013). Towards Hyper-Diversified European Cities. Utrecht: Utrecht University, Faculty of Geosciences. 
Vandrick, S. (2009). Interrogating Privilege: Reflections of a Second Language Educator. Michigan: University of Michigan Press.

Willard-Traub, M. (2006). Reflections on academe: scholarly writing and the shifting subject. College English, 68(4), 422-432. 